\title{
Exogenous application of nitric oxide and thiourea regulates on growth and some key physiological processes in maize (Zea mays L.) plants under saline stress.
}

\author{
Cengiz Kaya1' * , Osman Sönmez', Muhammed Ashraf², Tahir Polat \\ Levent Tuna ${ }^{4}$, Salih Aydemir' \\ 'Harran University, Faculty of Agriculture, Department of Soil Science \& Plant Nutrition, Șanlıurfa, Turkey \\ ${ }^{2}$ University College of Agriculture, University of Sargodha, Sargodha, Pakistan. \\ ${ }^{3}$ Harran University, Faculty of Agriculture, Department of Field Plants, Șanlıurfa, Turkey \\ ${ }^{4}$ Muğla University, Faculty of Science, Department of Biology, Muğla, Turkey \\ *Corresponding author e-mail : c_kaya70@yahoo.com \\ Received : 17.12.2013
}

Accepted: 14.04.1014

\begin{abstract}
Effect of exogenously applied nitric oxide (NO) and thiourea (TU) in combination was examined in maize plants under saline stress. Seedlings of two maize cultivars (DK 5783 and Apex 836) were grown in pots containing soil salinized with 0 or $100 \mathrm{mM} \mathrm{NaCl}$ dissolved in irrigation water. Two levels of $\mathrm{NO}$ $+\mathrm{TU}(3+400$ or $6+500 \mathrm{mg} / \mathrm{L})$ were applied as presowing seed treatment or through leaves of 10-day old maize seedlings. Saline stress significantly suppressed plant fresh biomass, leaf water potential and chlorophyll content, but increased electrolyte leakage in both cultivars. However, these reductions were higher in Apex 836 than those in DK 5783. Both treatments of combined NO and TU as seed soaking or foliar application were effective in mitigating the adverse effects of saline stress on shoot growth. Seed treatments of both levels of combined $\mathrm{NO}$ and $\mathrm{TU}$ were more effective in terms of improvement in fresh weights of DK 5783 than foliar treatments. Leaf $\mathrm{Na}^{+}$contents increased whereas those of $\mathrm{N}$ and $\mathrm{P}$ decreased in maize plants under saline regime. Application of Both modes of treatment of combined $\mathrm{NO}$ and $\mathrm{TU}$ increased the contents of $\mathrm{N}$ and $\mathrm{P}$, but decreased that $\mathrm{NO}$ and $\mathrm{TU}$ through both modes increased $\mathrm{Na}+$ in salt stressed maize plants. The results of the present study indicate that application of $\mathrm{NO}$ and TU compounds in combination alleviated the detrimental effects of salinity and increased resistance to salinity in the maize plants by improving plant growth
\end{abstract}

Keywords: Corn, salinity, nitric oxide, thiourea

\section{INTRODUCTION}

Reduced crop resistance to salinity is a principal problem in stabilization of crop performance under stressful environments (Bassetti and Westgate, 1993; Chaudhry et al., 2000). Consequently, development of stress resistance in crop plants is considered a valid approach by both breeders and molecular biologists (Bartels and Nelson, 1994). Although proper evaluation of genetic modifications for improved stress resistance is gaining considerable attention by plant biologists, there is still a serious lack of concepts, directions and protocols for accurate measuring and inducing stress resistance in plants. This has probably been due to the fact that most stress resistance traits are multigenic in nature. Despite the fact that the development of stress tolerance trait has been achieved in some crop species, differences in stress tolerance capability at various growth stages is posing a major hurdle towards a significant success (Ashraf and Harris, 2004).

However, these techniques are often costly, may take long time to be successful, or even may not produce desirable results. In this situation, use of growth substances provides a short-term solution to overcome environmental stresses. In recent times, attention has been diverted to the improvement of crops for stress tolerance by enhanced biosynthesis or exogenous application of growth substances (Naidu and Williams, 2004; Ouan et al., 2004) and this approach can be quite successfully applied to 
important crop species. Of a variety of growth substances, thiourea is believed to play an important role in oxidative stress defense system. For example, Srivastava et al. (2010) while working with Brassica juncea have shown that exogenously applied thiourea can effectively alleviate the inhibitory effects of saline stress on B. juncea seeds by regulating signaling mechanisms. However, the effectiveness of thiourea and related growth regulators has been reported to depend on plant species, environmental conditions, and concentration of soil salt solution. Thiourea has been reported to improve crop productivity in maize (Sahu and Solanki, 1991, Sahu et al., 1993) and wheat (Sahu and Singh, 1995).

Nitric oxide (NO), being a signal molecule is involved in responses of plants to both biotic and abiotic stresses (Crawford and Guo, 2005; Delledonne, 2005). The addition of NO to growth medium has been reported to promote seed germination (Beligni and Lamattina, 2001), and regulate growth of plant tissues (Durner and Klessig, 1999; Pagnussat, et al., 2003). In view of some studiesit is believed that $\mathrm{NO}$ protects plants against stress-induced oxidative stress (Garc'ia-Mata and Lamattina, 2001; Shi et al., 2005). So, in the present study, the effects of nitric oxide and thiourea applied in combination as seed soaking or applied through leaves were observed on key plant growth attributes and mineral nutrition status of two maize cultivars with differential salinity tolerance grown under saline conditions.

\section{MATERIALS AND METHODS}

\section{Plant culture and treatments}

The experiment was conducted in a glasshouse at the Research Station of the Agriculture Faculty, University of Harran (Turkey) during May and June 2013 with maize (Zea mays L. CVs. DK5783 and Apex 836). Five seeds were sown in each pot containing air-dried soil $(10 \mathrm{~kg}$ in each pot). The texture of the soil used was loamy clay; $\mathrm{pH}$ (1:2.5 water, v:v) was 7.3, EC $0.45 \mathrm{dS} / \mathrm{m}, \mathrm{K} 1.40 \mathrm{~g} / \mathrm{kg}$, and $\mathrm{N} 1.25 \mathrm{~g} / \mathrm{kg}$. Nitrogen, $\mathrm{P}_{2} \mathrm{O}_{5}$ and $\mathrm{K}_{2} \mathrm{O}$ were mixed in the soil at the rates of 100,50 and 120 $\mathrm{mg} / \mathrm{kg}$ as granular urea triple superphosphate and potassium sulfate, respectively.

After germination, the seedlings were thinned to three in each pot, and then placed in a glasshouse for further 35 days at $27 \pm 2 \circ \mathrm{C}$ with mean daytime relative humidity $60-70 \%$. Before the initiation of the salt treatments, plants were allowed to grow for further 7 days so as to get them established well. The experiment layout was a randomized complete block design with three replicates. The volume of water applied every day to the root-zone of plants in each container ranged from $50 \mathrm{~mL}$ to $500 \mathrm{~mL}$ depending on the size of plants and time from planting.

The two salt treatments applied via irrigation water were: control (no NaCl) and $100 \mathrm{mM}$ of $\mathrm{NaCl}$. Two levels of nitric oxide (3 and $6 \mathrm{mg} / \mathrm{l}$ ) and thiourea (400 and $500 \mathrm{mg} / \mathrm{l}$ ) in combination as seed soaking or foliar spray were applied 10 days after seed germination. Sodium nitroprusside (SNP) was used as NO donors. Before germination of seeds, they were disinfected with sodium hypochlorite solution (1\% v/v) and then washed with distilled water. For pretreatment of $\mathrm{NO}$ plus DU as seed soaking, the seeds were soaked for 24 h either in 3 mg/l NO plus 400 mg/l TU or 6 mg/l $\mathrm{NO}$ plus $500 \mathrm{mg} / \mathrm{l} \mathrm{TU}$ solution. Plants were sprayed once a week with $\mathrm{NO}$ and thiourea solution (50 $\mathrm{ml} / \mathrm{pot})$ prepared in $0.01 \%$ tween-20 $\left(\mathrm{C}_{58} \mathrm{H}_{114} \mathrm{O}_{26}\right)$, a surfactant. The spray was started 10 days after germination occurred and continued up to day 35. Salt stress was maintained by adding $5.85 \mathrm{~g} \mathrm{NaCl}$ $\mathrm{kg}^{-1}$ to the soil via irrigation water prior to planting. Addition of $5.85 \mathrm{~g} \mathrm{~kg}^{-1} \mathrm{NaCl}$ to the soil brought the salt level to $100 \mathrm{mM}$. The EC value of the soil was monitored weekly till the termination of the experiment.

At the end of the experiment, fresh weights, inorganic nutrients, chlorophyll content, electrolyte leakage and leaf water potential were determined.

\section{Chlorophyll determination}

Chlorophyll content was determined following Strain and Svec (1966). One g of fully expanded youngest leaves was triturated in 90\% acetone solution. The absorbance of the supernatant was measured with a UVNisible spectrophotometer (Shimadzu UV-1201 V, Japan).

\section{Leaf water potential}

For leaf water potential measurement, a fully youngest leaf (mainly 3rd leaf from top) was detached from each plant at 8.00 a.m. and its water potential measured using a pressure chamber (PMS model 600, USA).

\section{Electrolyte leakage}

Electrolyte leakage was measured following the formula Dionisio-Sese and Tobita (1998) Using the

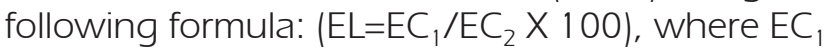


is initial electrical conductivity and $\mathrm{EC}_{2}$ electrical conductivity after subjecting the plant material to autoclave.

\section{Nutrient analysis}

Total $\mathrm{N}$ was determined using the Kjeldahl method using dry plant material. For the analysis of other inorganic nutrients, the dried and well ground samples were ashed in a muffle furnace at $550^{\circ} \mathrm{C}$ for $6 \mathrm{~h}$. The white ash was dissolved in $5 \mathrm{~mL}$ of $2 \mathrm{M}$ hot $\mathrm{HCl}$, and made the final volume to 50 $\mathrm{mL}$ with distilled water. Sodium was analyzed using an ICP (Chapman and Pratt, 1982) and P following the Vanadate-molybdate method.

\section{Statistical analysis}

Analysis of variance (ANOVA) of data for all attributes was worked out using the statistical package SAS version 9.1 (SAS Institute Inc., ary, NC, USA). All mean values within each parameter were compared using the LSD test at the $5 \%$ probability level.

\section{RESULTS AND DISCUSSION}

\section{Fresh weigh and total chlorophyll content}

The shoot fresh mass and total chlorophyll of both cultivars of maize plants was reduced under salinity conditions compared to the control plants (Table 1). These results are in conformity with some previously published reports on some cereal crops, e.g. rice (Arshadullah et al., 201 1), sorghum (Bashir et al., 2011), wheat (Perveen et al., 2011, 2012), and pearl millet (Hussain et al., 2008). The chlorophyll content of leaves generally decreased under salt stress. The decrease in chlorophyll could be due to the biosynthesisof proteolytic enzymes such as chlorophyllase, which carries out chlorophyll degradation (Sabater and Rodriguez,
1978) as well as damage to the photosynthetic apparatus (Yasseen, 1983). However, reductions in fresh weight and total chlorophyll were higher in the salt sensitive cultivar Apex 836 than those in the salt tolerant cultivar DK 5783. Foliar and seed applications of $\mathrm{NO}$ and $\mathrm{TU}$ in combination at both doses increased the fresh mass and total chlorophyll in both cultivars grown at saline regime, though the values were still significantly lower than those of the control plants (Table 1). The effect of seed application of combined $\mathrm{NO}$ and TU was slightly higher than that of foliar application in increasing all these parameters in the salt-stressed maize plants. It has been reported that application of NO caused an increase in shoot fresh weight under saline conditions (Kausar and Shahbaz, 2013). Some earlier published reports on different crops such as rice, maize, tomato and soybean have shown that foliar-applied NO improved plant growth under saline stress, which was ascribed to improved activities of some key antioxidant enzymes (Zhang et al., 2004; Hu et al., 2005; Wu et al., 20111.

\section{Leaf water potential and membrane stability}

Substantial electrolyte leakage (EL) was noticed due to salt stress. Electrolyte leakage was considerably greater in salt-stressed plants than those in the non-stressed plants (Table 2). The increase in electrolyte leakage recorded under salt stress could be partly due to the decreased chlorophyll content (Kaya et al., 2001). Increased electrolyte leakage was reported to be associated with reductions in leaf senescenc-induced chlorophyll concentration (Dhindsa et al., 1981; Chen et al., 1991). Increase in the EL values of salinized plants was higher in the salt sensitive cultivar Apex 836 than that in salt tolerant cultivar

Table 1. Fresh weight and total chlorophyll (mg/kg Fw) of different cultivars of maize grown in salt with or without different levels of combined nitric oxide and thiourea (mg/l) applied as different modes

\begin{tabular}{lcllll}
\hline \multirow{2}{*}{$\begin{array}{l}\text { Cultivars } \\
\text { Treatments }\end{array}$} & \multicolumn{2}{c}{ DK 5783 } & \multicolumn{2}{c}{ Apex 836 } & Treatments Vs \\
\cline { 2 - 4 } & FW $(\mathrm{g} / \mathrm{p})$ & Chl. & FW/g/p) & Chl. & \\
\hline C & $16.3 \mathrm{a}$ & $1256 \mathrm{a}$ & $12.3 \mathrm{a}$ & $1198 \mathrm{a}$ & $*$ \\
S & $9.7 \mathrm{~d}$ & $1056 \mathrm{c}$ & $6.7 \mathrm{c}$ & $1005 \mathrm{~d}$ & $*$ \\
SNO+TU 3+400 & $12.3 \mathrm{~b}$ & $1132 \mathrm{~b}$ & $7.2 \mathrm{~b}$ & $1074 \mathrm{~b}$ & $*$ \\
SNO+TU6+500 & $12.3 \mathrm{~b}$ & $1136 \mathrm{~b}$ & $7.3 \mathrm{~b}$ & $1082 \mathrm{~b}$ & $*$ \\
fNO+TU 3+400 & $10.7 \mathrm{c}$ & $1136 \mathrm{~b}$ & $7.2 \mathrm{~b}$ & $1046 \mathrm{c}$ & $*$ \\
fNO+TU 6+500 & $11.4 \mathrm{C}$ & $1139 \mathrm{~b}$ & $7.3 \mathrm{~b}$ & $1036 \mathrm{C}$ & $*$ \\
\hline
\end{tabular}

NO: Nitric oxide; TU: Thiourea; C: control; S: 100 mM NaCl; s:seed application; f: foliar application (mg/l).

Within each column, means with different letters are significantly different ( $P \leq 0.05)$.

*LSD test: Shows significant differences between treatments and cultivars $(P<0.005)$. 
DK 5783. However, both seed and foliar application of combined $\mathrm{NO}$ and thiourea at both doses to the salt-stressed plants caused a substantial decrease in EL in the leaves compared with the salt treated plants which received neither seed nor foliar application of combined $\mathrm{NO}$ and $\mathrm{T}$ (Table 2). The effects of seed and foliar application of $\mathrm{NO}$ and $\mathrm{T}$ in combination were similar in decreasing $E L$ in the salt stressed maize plants. regime (Table 3). Both modes of application of combined $\mathrm{NO}$ and $\mathrm{TU}$ raised tissue $\mathrm{N}$ and $\mathrm{P}$ contents, but suppressed that of $\mathrm{Na}+$ in salt stressed maize plants In most cases, seed application of combined $\mathrm{NO}$ and TU was more effective in reducing $\mathrm{Na}$ and increasing $\mathrm{N}$ and $\mathrm{P}$ contents compared to the other mode of application.

Table 2. Leaf water potential ( $\Psi$ I : MPa) and membrane stability (MS) of different cultivars of maize grown in salt with or without different levels of combined nitric oxide and thiourea (mg/l) applied as different modes

\begin{tabular}{|c|c|c|c|c|}
\hline \multirow{2}{*}{$\begin{array}{l}\text { Cultivars } \\
\text { Treatments }\end{array}$} & \multicolumn{2}{|c|}{ DK 5783} & \multicolumn{2}{|c|}{ Apex 836} \\
\hline & $\Psi \mid$ & MS (\%) & $\Psi \mid$ & MS (\%) \\
\hline C & -0.35 a & $16 \mathrm{C}$ & -0.32 a & $19 c$ \\
\hline$S$ & $-1.45 d$ & 24 a & $-1.58 d$ & 29a \\
\hline sNO+TU 3+400 & $-1.36 c$ & $21 \mathrm{~b}$ & $-1.41 \mathrm{C}$ & 26ab \\
\hline sNO+ TU $6+500$ & $-1.33 \mathrm{bc}$ & $21 \mathrm{~b}$ & $-1.39 c$ & $25 b$ \\
\hline $\mathrm{fNO}+\mathrm{TU} 3+400$ & $-1.34 b c$ & $21 \mathrm{~b}$ & $-1.39 c$ & $25 b$ \\
\hline $\mathrm{fNO}+\mathrm{TU} \quad 6+500$ & $-1.28 \mathrm{~b}$ & $21 \mathrm{~b}$ & $-1.27 b$ & 26ab \\
\hline
\end{tabular}

NO: Nitric oxide; TU: Thiourea C: control; S: 100mM NaCl; s:seed application; f: foliar application (mg/I). Within each column, means with different letters are significantly different $(P \leq 0.05)$.

\section{Mineral elements}

Salinity increased Na+ contents but decreased those of $\mathrm{N}$ and $\mathrm{P}$ in the leaves of both cultivars of maize plants. Addition of salt stress to the root growing medium perturbs ion homeostasis mechanism due to accumulation of toxic ions in different plant parts (Munns and Tester, 2008) that alters plant physiological processes thereby causing reduced growth. Na content was higher in the salt sensitive cultivar Apex 836 than that in the salt tolerant cultivar DK 5783 grown in saline

\section{CONCLUSIONS}

Overall, salt stress induced inhibitory effects on growth attributes of maize plants. However, exogenously applied $\mathrm{NO}$ and thiourea in combination enhanced to some extent stress tolerance in maize plants by enhancing shoot fresh weights, chlorophyll content, leaf water potential, $\mathrm{N}$ and $\mathrm{P}$ content and by decreasing electrolyte leakage and $\mathrm{Na}$ content in the maize plants under saline conditions.

Table 3. Sodium, nitrogen and phosphorous concentrations $(\mathrm{mmol} / \mathrm{kg})$ of different cultivars of maize grown in salt with or without different levels of combined nitric oxide and thiourea (mg/l) applied as different modes

\begin{tabular}{|c|c|c|c|c|c|c|}
\hline \multirow{2}{*}{$\begin{array}{l}\text { Cultivars } \\
\text { Treatments }\end{array}$} & \multicolumn{3}{|c|}{ DK 5783} & \multicolumn{3}{|c|}{ Apex 836} \\
\hline & $\mathrm{Na}$ & $\mathrm{N}$ & $\mathrm{P}$ & $\mathrm{Na}$ & $\mathrm{N}$ & $P$ \\
\hline $\mathrm{C}$ & $34 d$ & $1150 \mathrm{~b}$ & 66 a & $31 d$ & 1125 a & 62 a \\
\hline$S$ & 325 а & 885 d & $34 c$ & 395 а & $840 \mathrm{~d}$ & $29 \mathrm{C}$ \\
\hline sNO+TU 3+400 & $266 c$ & $1150 \mathrm{~b}$ & $44 \mathrm{~b}$ & $334 c$ & $1021 \mathrm{C}$ & $32 \mathrm{c}$ \\
\hline sNO+TU 6+500 & $275 \mathrm{bc}$ & 1190 a & $44 \mathrm{~b}$ & $332 \mathrm{c}$ & 1052 b & $34 \mathrm{c}$ \\
\hline $\mathrm{fNO}+\mathrm{TU} 3+400$ & $285 \mathrm{~b}$ & $1020 \mathrm{c}$ & $45 \mathrm{~b}$ & $351 \mathrm{~b}$ & $1012 \mathrm{c}$ & $42 \mathrm{~b}$ \\
\hline $\mathrm{fNO}+\mathrm{TU} 6+500$ & $286 \mathrm{~b}$ & $1024 \mathrm{c}$ & $44 \mathrm{~b}$ & $353 \mathrm{~b}$ & $1035 \mathrm{~b}$ & $42 \mathrm{~b}$ \\
\hline
\end{tabular}

NO: Nitric oxide; TU: Thiourea C: control; S: $100 \mathrm{mM} \mathrm{NaCl}$; s:seed application; f: foliar application (mg/l). Within each column, means with different letters are significantly different $(P \leq 0.05)$ 


\section{ACKNOWLEDGEMENT}

This research was supported by The Scientific and Technical Research Council of Turkey (TOVAG1120375).

\section{REFERENCES}

Agastian, P., Kingsley, S.J., Vivekanandan, M., 2000. Effect of salinity on photosynthesis and biochemical characteristics in mulberry genotypes. Photosynthetica 38, 287-290

Arshadullah, M., Rasheed, M., Zaidi, S.A.R., 2011 . Salt tolerance of different rice cultivars for their salt tolerance under salt-affected soils. Int. Res. J. Agri. Sci. Soil Sci. 1, 183184

Bashir, F., Ali, M., Hussain, K., Majeed, A., Nawaz, K, 2011. Morphological variations in sorghum (Sorghum bicolor L.) under different levels of Na2SO4 salinity. Bot. Res. Int. 4, 1-3

Beligni, M.V., Lamattina, L., 2001 . Nitric oxide: A nontraditional regulator of plant growth. Trends Plant Sci. 6, 508-509.

Crawford, N.M., Guo, F.O., 2005. New insights into nitric oxide metabolism and regulatory functions. Trends Plant Sci. 10, 195-200

Delledonne, M., 2005. NO news is good news for plants, Curr. Opin. Plant Biol. 8, 1-7

Beligni, M.V., Lamattina, L., 2000. Nitric oxide stimulates seed germination and de-etiolation, and inhibits hypocotyl elongation, three light-inducible responses in plants. Planta $210,215-221$.

Chapman, H.D., Pratt, P.F., 1982. Methods of Plant Analysis. I. Methods of analysis for soils, plants and water Riverside, CA: Chapman Publishers.

Chen, C.T., Li, C.C., Kao, C.H., 1991. Senescence of rice leaves XXXI. Changes of chlorophyll, protein and polyamine contents and ethylene production during senescence of a chlorophyll-deficient mutant. J. Plant Growth Reg. 10, 201 205

Delledonne, M., 2005. NO news is good news for plants. Curr. Opin. Plant Biol. 8, 1-7

Dhindsa, R.S., Plumb-Dhindsa, P., Thorpe, T.A., 1981. Leaf senescence correlated with increased levels of membrane permeability and lipid peroxidation, and decreased levels of superoxide dismutase and catalase. J. Exp. Bot. 32, 93-101

Dionisio-Sese, M.L., Tobita, S., 1998. Antioxidant responses of rice seedlings to salinity stress. Plant Sci. 135, 19

Durner, J., Klessig, D.F., 1999. Nitric oxide as a signal in plants, Curr. Opin. Plant Biol. 2, 369-374

Farooq, M., Basra, S.M.A., Wahid, A., Rehman, H., 2009. Exogenously applied nitric oxide enhances the drought tolerance in fine grain aromatic rice (Oryza sativa L.). J. Agron. Crop Sci. 14, 220-225
Gadallah, M.A.A., 1999. Effects of proline and glycinebetaine on Vicia faba response to salt stress. Biol. Plant. 42, 249-257.

Garc'ıa-Mata, C., Lamattina, L., 2001. Nitric oxide induces stomatal closure and enhances the adaptive plant responses against drought stress. Plant Physiol. 126, $1196-$ 1204

Hernandez, J.A., Olmos, E., Corpas, F.J., Sevilla, F., del Rio, L.A., 1995. Salt-induced oxidative stress in chloroplasts of pea plants. Plant Sci. 105, 151-167.

Hu, X.S., Neill, J., Tang, Z., Cai, W., 2005. Nitric oxide mediates gravitropic bending in soybean roots. Plant Physiol. 137, 663-670

Hussain, K., Ashraf, M., Ashraf, M.Y., 2008. Relationship between growth and ion relation in pearl millet (Pennisetum glaucum L.) at different growth stages under salt stress. Afr. J. Plant Sci. 2, 23-27

Kausar F., Shahbaz, M. 2013. Interactive effect of foliar application of nitric oxide and salinity on wheat (Triticum aestivum). Pak. J. Bot. 45, 67-73

Kaya, C., Kirnak, H., Higgs, D., 2001 . Enhancement of growth and normal growth parameters by foliar application of potassium and phosphorus in tomato cultivars grown at high (NaCl) salinity. J. Plant Nutr. 24, 357-367

Munns, R, Tester, M., 2008. Mechanisms of salinity tolerance. Annu. Rev. Plant Biol. 59, 651-681

Naidu, B.P., Williams, R., 2004. Seed treatment and foliar application of osmoprotectants to increase crop establishment and cold tolerance at flowering in rice. A Report of the Rural Industries Research and Development Corporation Project No. CST-2A. CSIRO Tropical Agriculture, Brisbane

Pagnussat, G.C., Lanteri, M.L., Lamattina, L., 2003. Nitric oxide and cyclic GMP are messengers in the indole acetic acid-induced adventitious rooting process. Plant Physiol. $132,1241-1248$

Perveen, S., Shahbaz, M., Ashraf, M., 2011. Modulation in activities of antioxidant enzymes in salt stressed and nonstressed wheat (Tritcum aestivum L.) plants raised from seed treated with tricontanol. Pak. J. Bot. 43, 2463-2468.

Perveen, S., Shahbaz, M., Ashraf, M., 2012. Changes in mineral composition, uptake and use efficiency of salt stressed wheat (Triticum aestivum L.) plants raised from seed treated with triacontanol. Pak. J. Bot. 44, 27-35

Quan, R., Shang, M., Zhang, H., Zhao, Y., Zhang, J., 2004. Engineering of enhanced glycine betaine synthesis improves drought tolerance in maize. Plant Biotech J 2, 477-486

Sabater, B., Rodriguez, M.T., 1978. Control of chlorophyll degradation in detached leaves of barley and oat through effect of kinetin on chlorophyllase. Physiol. Plant. 43, 274-276.

Sahu, M.P., Singh, D., 1995. Role of thiourea in improving productivity of wheat (Triticum aestivum L.). Plant Growth Regul. 14, 169-173 
Sahu, M.P., Solanki, N.S., Dashora, L.N., 1993. Effects of thiourea, thiamine and ascorbic acid on growth and yield of maize (Zea mays L.). J. Agron. Crop Sci. 171, 65-69

Sahu, M.P., Solanki, N.S., 1991. Role of sulphydryl compounds in improving dry matter partitioning and grain production of maize (Zea mays L.). J. Agron. Crop Sci. 167, 356-359.

Shi, S.Y., Wang, G., Wang, Y.D., Zhang, L.A., Zhang, L.X., 2005. Protective effect of nitric oxide against oxidative stress under ultraviolet-B radiation, Nitric Oxide, 13, 1-9.

Srivastava, A.K., Ramaswamy, N.K., Suprasanna, P., D'Souza, S. F., 2010. Genome-wide analysis of thioureamodulated salinity stress responsive transcripts in seeds of Brassica juncea: identification of signalling and effector components of stress tolerance. Ann. Bot.106, 663-674
Strain, H.H., Svec, W.A., 1966. In: The chlorophylls, Vernon, L.P. and Seely, S.R. (eds), Acad. Press, New York. pp. 21.

Wu, X., Zhu, W., Zhang, H., Ding, H., Zhang, H.J., 2011. Exogenous nitric oxide protects against salt-induced oxidative stress in the leaves from two genotypes of tomato (Lycopersicon esculentum Mill.). Acta Physiol. Plant. 33, 1199-1209.

Yasseen, B.T., 1983. An analysis of the effects of salinity on leaf growth in Mexican wheats. UK, The University of Leeds. Ph. D. thesis.

Zhang, Y.Y., Liu, J., Liu, Y.L., 2004. Nitric oxide alleviates growth inhibition of maize seedlings under salt stress. J.Plant Physiol. Mol. Biol. 30, 455-459 